\title{
The Fuzzy Comprehensive Evaluation of Colleges and Universities Teaching Quality
}

\author{
Wantao Liu $^{1, \text { a }}$ \\ ${ }^{1}$ Graduate School of Harbin University of Science and Technology, Harbin, 150080, China \\ aemail: Iwt11231@hrbust.edu.cn
}

Keywords: component; formatting; style; styling; insert

\begin{abstract}
Teaching Quality Evaluation is an important part of teaching management. In this paper, the conventional evaluation method for qualitative analysis, with a certain degree of subjectivity and one-sidedness, not comprehensive and accurate, proposed a fuzzy comprehensive method to the scientific quantitative evaluation, application of fuzzy systems theory, fuzzy evaluation model, comprehensive assessment and scientific quantitative calculation of the inaccuracies in the evaluation of the quality of teaching. By actual specific numerical example, show that the method is simple , easy , and accurate.
\end{abstract}

\section{Introduction}

The evaluation of the quality of teaching is an important part of teaching management, is a highly scientific work, Literature [1][2][3] involves education, psychology, management science, and other disciplines and multiple fields. In the past, the most of judge method of Literature [4] is qualitative analysis, with a certain degree of subjectivity and one-sidedness, not comprehensive and accurate. In this paper, a fuzzy system theory, developing an evaluation model, for the inaccuracies in the evaluation of the quality of teaching to comprehensive assessment of quantitative and scientific computing.

\section{Mathematical Model}

Improved mathematical models in the literature [5] assume that evaluating a objects set is $X=\left\{x_{1}, x_{2}, \ldots, x_{n}\right\}$, assessment experts set is $S=\left\{s_{1}, s_{2}, \ldots, s_{k}\right\}$, evaluation index set is $U=\left\{u_{1}, u_{2}, \ldots, u_{n}\right\}$, remark set is $V=\left\{v_{1}, v_{2}, \ldots, v_{m}\right\}$. To each evaluation object $x_{i}(i=1,2, \cdots, n)$, each experts $s_{i}(i=1,2, \cdots, k)$ according to their own point of view on the evaluation index to determine, determination result belongs to one of remark set $\mathrm{V}$, order to determine the fuzzy relationship matrix of specific assessment objects.

$$
\boldsymbol{R}=\left[\begin{array}{cccc}
r_{11} & r_{12} & \cdots & r_{1 m} \\
r_{21} & r_{22} & \cdots & r_{2 m} \\
\cdots & \cdots & \cdots & \cdots \\
r_{n 1} & r_{n 2} & \cdots & r_{n m}
\end{array}\right]
$$

In the formula, $r_{i j}$ said i-assessment indicators, the class jassess level score, the formula is:

$r_{i j}=\frac{v_{i j}}{k}$

I-assessment indicators where denotes the specific object, experts give the number of class $\mathrm{j}$ reviews, $\mathrm{k}$ is the total number of experts, This article selected the evaluation index set:

$$
\begin{aligned}
& U=\left\{u_{1}, u_{2}, u_{3}, u_{4}, u_{5}\right\}= \\
& \{\text { purposes, attitude, content, } \\
& \text { methods, effectiveness }
\end{aligned}
$$

The 


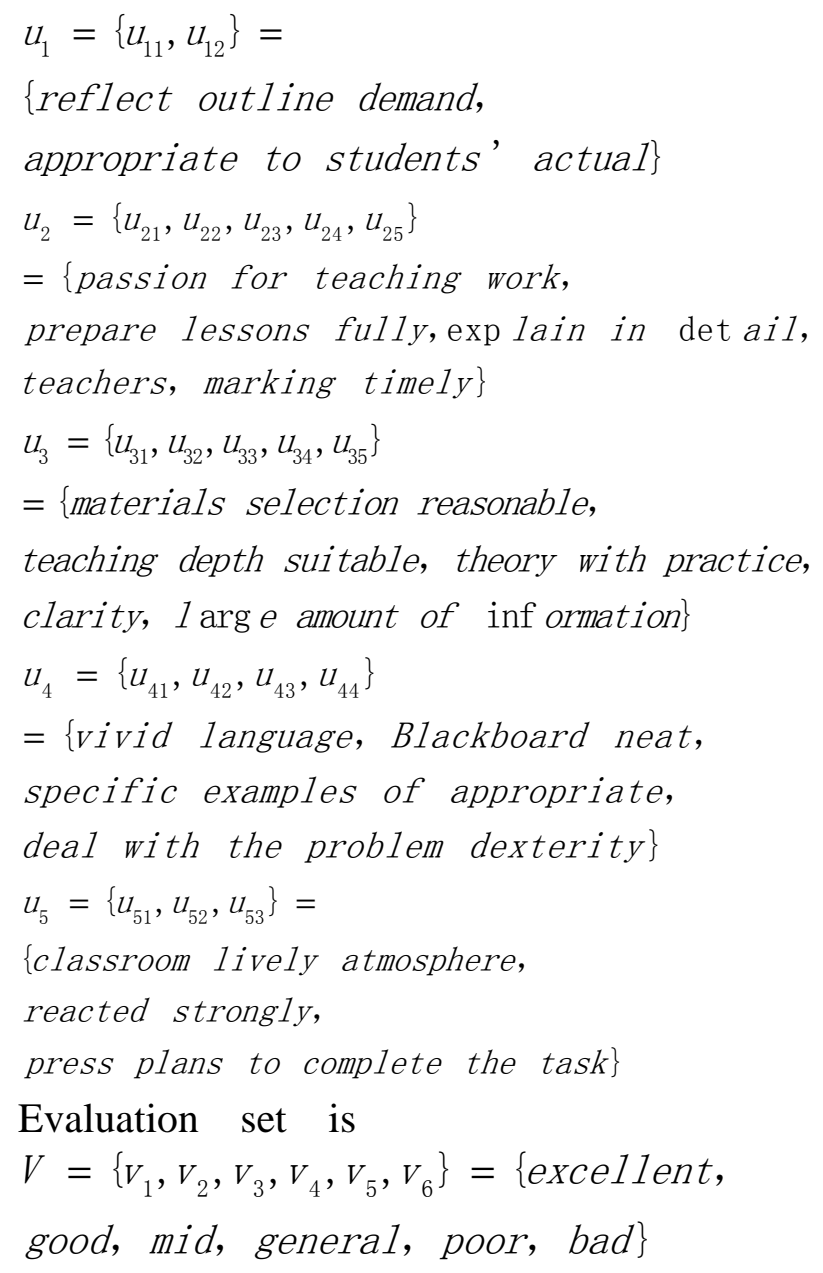

The role and impact of the various assessment indicators, in the comprehensive assessment, weight coefficient matrix given the indicators assessed by experts $\boldsymbol{W}=\left[w_{1}, w_{2}, \cdots, w_{n}\right]$, the combination of weighting matrix $\boldsymbol{W}$ and fuzzy relationship matrix $\boldsymbol{R}$, is a comprehensive evaluation of the assessment object[6][7][8].

\section{Comprehensive Evaluation Method}

Definition $A=W \cdot R$,for object $x_{i}$, seen $A_{i}=W \cdot R=\left\{x_{i 1}, x_{i 2}, \cdots, x_{i m}\right\}$. According to the principle of maximum degree of membership, if $v_{i}=\max \left\{x_{i 1}, x_{i 2}, \cdots, x_{i m}\right\}$, then the rating of object $x_{i}$ is $v_{i}$.

If the assessed object more, such as university courses can be divided into public courses, basic courses and specialized courses in three categories, it is difficult to reasonable given the weight distribution, multi-level evaluation is needed [9]. First comprehensive evaluation of each class, and each class as a judge of a single factor, a total of three single factor, the last of the three single-factor comprehensive evaluation to their respective weights, the second-level comprehensive evaluation, in order to achieve a reasonable effect.

$$
A=W \cdot R=W \cdot\left[\begin{array}{l}
W_{1} \cdot R_{1} \\
W_{2} \cdot R_{2} \\
W_{3} \cdot R_{3}
\end{array}\right]
$$

$\boldsymbol{W}$ is the three single factor weighting matrix $\boldsymbol{W i}$ each category subdivided each index weighting matrix, so that you can judge the results on two judges. All kinds of factors contain too much can also be subdivided by three or more levels judged to come to a better comprehensive evaluation. 


\section{Specific examples}

Here we have a certain teacher evaluation process, for example, to illustrate the comprehensive evaluation process. This paper selected 10 experts on a teaching evaluation survey, as shown in Table 1.

Table 1 teachers teaching evaluation questionnaire

\begin{tabular}{|c|c|c|c|c|c|c|c|}
\hline \multirow{2}{*}{ main factors } & \multirow{2}{*}{ Sub-factors } & \multicolumn{6}{|c|}{ Evaluation (people) } \\
\hline & & Excellent & Good & Mid & General & Poor & bad \\
\hline \multirow{2}{*}{$\begin{array}{l}\text { Teaching } \\
\text { Purpose }\end{array}$} & Reflect the program requirements & 3 & 5 & 1 & 1 & 0 & 0 \\
\hline & Appropriate to students' actual & 2 & 4 & 2 & 2 & 0 & 0 \\
\hline \multirow{5}{*}{$\begin{array}{l}\text { Teaching } \\
\text { Attitude }\end{array}$} & Passion for teaching work & 0 & 2 & 5 & 2 & 1 & 0 \\
\hline & Lesson planning in earnest & 1 & 3 & 3 & 3 & 0 & 0 \\
\hline & Explain carefully & 3 & 5 & 2 & 0 & 0 & 0 \\
\hline & Teachers & 1 & 3 & 2 & 3 & 1 & 0 \\
\hline & Marking timely & 2 & 2 & 3 & 3 & 0 & 0 \\
\hline \multirow{5}{*}{$\begin{array}{l}\text { Teaching } \\
\text { Content }\end{array}$} & Materials selection and reasonable & 2 & 4 & 4 & 0 & 0 & 0 \\
\hline & Teaching depth suitable & 1 & 5 & 3 & 0 & 1 & 0 \\
\hline & Theory with practice & 0 & 3 & 4 & 2 & 1 & 0 \\
\hline & Well organized & 2 & 2 & 4 & 2 & 0 & 0 \\
\hline & Large amount of information & 3 & 3 & 3 & 1 & 0 & 0 \\
\hline \multirow{4}{*}{$\begin{array}{l}\text { Teaching } \\
\text { Means }\end{array}$} & Vivid language & 2 & 5 & 2 & 1 & 0 & 0 \\
\hline & Blackboard neat & 0 & 2 & 5 & 3 & 0 & 0 \\
\hline & Specific examples of appropriate & 3 & 3 & 4 & 0 & 0 & 0 \\
\hline & Flexible handling problems & 2 & 2 & 6 & 0 & 0 & 0 \\
\hline \multirow{3}{*}{$\begin{array}{l}\text { Teaching } \\
\text { Effect }\end{array}$} & Classroom atmosphere & 3 & 2 & 4 & 1 & 0 & 0 \\
\hline & Reflect the strong & 3 & 4 & 2 & 1 & 0 & 0 \\
\hline & The successful completion of tasks on schedule & 5 & 2 & 3 & 0 & 0 & 0 \\
\hline
\end{tabular}

According to the different degrees of importance of various factors in the evaluation items, given different weights, specific allocation is as follows:

$$
\begin{aligned}
& W=\left[\begin{array}{lllll}
0.1 & 0.3 & 0.3 & 0.2 & 0.1
\end{array}\right] \\
& W_{1}=\left[\begin{array}{ll}
0.5 & 0.5
\end{array}\right] \\
& W_{2}=\left[\begin{array}{lllll}
0.1 & 0.2 & 0.3 & 0.2 & 0.2
\end{array}\right] \\
& W_{3}=\left[\begin{array}{lllll}
0.2 & 0.25 & 0.25 & 0.2 & 0.1
\end{array}\right], \quad W_{4}=\left[\begin{array}{llll}
0.25 & 0.2 & 0.25 & 0.3
\end{array}\right], \\
& \boldsymbol{W}_{5}=\left[\begin{array}{lll}
0.3 & 0.5 & 0.2
\end{array}\right] \text {. }
\end{aligned}
$$

The following comprehensive evaluation:

$A_{1}=W_{1} \cdot R_{1}=\left[\begin{array}{llllll}0.25 & 0.45 & 0.15 & 0.15 & 0 & 0\end{array}\right]$

$A_{2}=W_{2} \cdot R_{2}=\left[\begin{array}{llllll}0.19 & 0.33 & 0.27 & 0.2 & 0.03 & 0\end{array}\right]$

$A_{3}=W_{3} \cdot R_{3}=\left[\begin{array}{llllll}0.135 & 0.35 & 0.365 & 0.1 & 0.05 & 0\end{array}\right]$

$A_{4}=W_{4} \cdot R_{4}=\left[\begin{array}{llllll}0.185 & 0.3 & 0.43 & 0.085 & 0 & 0\end{array}\right]$

$A_{5}=W_{5} \cdot R_{5}=\left[\begin{array}{llllll}0.34 & 0.3 & 0.38 & 0.08 & 0 & 0\end{array}\right]$

After the normalization processing, Fuzzy relationship matrix: 


$$
R=\left[\begin{array}{l}
A_{1} \\
A_{2} \\
A_{3} \\
A_{4} \\
A_{5}
\end{array}\right]=\left[\begin{array}{cccccc}
0.25 & 0.45 & 0.15 & 0.15 & 0 & 0 \\
0.19 & 0.32 & 0.26 & 0.2 & 0.03 & 0 \\
0.135 & 0.35 & 0.365 & 0.1 & 0.05 & 0 \\
0.185 & 0.3 & 0.43 & 0.085 & 0 & 0 \\
0.32 & 0.27 & 0.34 & 0.07 & 0 & 0
\end{array}\right]
$$

then

$$
A=W \cdot R=\left[\begin{array}{llllll}
0.186 & 0.333 & 0.3225 & 0.123 & 0.024 & 0
\end{array}\right]
$$

After the normalization processing

$$
\boldsymbol{A}=\left[\begin{array}{llllll}
0.188 & 0.327 & 0.326 & 0.125 & 0.034 & 0
\end{array}\right]
$$

The highest value of $\mathrm{A}$ is 0.327 , according to the principle of maximum degree of membership, found that teachers teaching evaluation results is good.

\section{Conclusion}

Uncertainty for teaching evaluation system itself, use of fuzzy comprehensive method to judge, scientific and rationality, either all things considered, and appropriate weights relationship. In this paper, the conventional evaluation method for qualitative analysis, with a certain degree of subjectivity and one-sidedness, not comprehensive and accurate, proposed a fuzzy comprehensive method to the scientific quantitative evaluation, application of fuzzy systems theory, fuzzy evaluation model, comprehensive assessment and scientific quantitative calculation of the inaccuracies in the evaluation of the quality of teaching. By actual specific numerical example, show that the method is simple in principle, convenience of calculation, practicability, is an effective means of evaluation.

\section{References}

[1] Zengke Zhang. Fuzzy Mathematics in automation technology [M]. Beijing: Tsinghua University Press, pp. 245-261 1997.

[2] Junmin Wei,Zhichao Zhu . Shuguang Liu. Fuzzy Control Technology [M]. Beijing: China Textile Press, pp.326-353. 2001.

[3] Xiaokang Zhou. Mathematical model of teaching quality assessment [J]. Teaching and Research,pp.31-45 1994(1).

[4] Qiaoyun WU,Gang CHANG,Wei CHAI,Chaojun JI,Zhengxi WANG. AHP-Fuzzy Comprehensive Evaluation on the Quality of Classroom Teaching in Military Colleges[C] Proceedings of the 2011 International Conference on Information ,Services and Management Engineering.vol.2.2011..pp.562-574.

[5] Yuexiao Han. Research on the Quality Evaluation of College Computer to Classroom Teaching Based on Fuzzy Comprehensive Evaluation[C] International Conference on E-Health Networking, Digital Ecosystems and Technologies Proceedings.Vol 2.2010.pp.287-299.

[6] Jinwei YANG. Sujuan YAN. Fuzzy Comprehensive Evaluation of Air Quality in Pingdingshan[C] Proceedings of 2011 IEEE International Conference on Waste Recycling,Ecology and Environment.2011.pp.469-472

[7] MENG Lihong. CHEN Yaning, LI Weihong ,ZHAO Ruifeng. Fuzzy Comprehensive Evaluation Model for Water Resources Carrying Capacity in Tarim River Basin,Xinjiang,China. Under the auspices of Knowledge Innovation Program of Chinese Academy of Sciences (No. KZCX2-YW-127);National Natural Science Foundation of China (No. 40671014, 90502007).pp.280-302.

[8] YUAN Zhen. WANG Hua. LIU Li-zhen. LIANG Tao. Researching the Comprehensive Use of Fuzzy Comprehensive Evaluation and Markov Chain[C]. Proceedings of 2009 IEEE International 
Symposium on IT in Medicine \& Education(ITME2009).pp.201-240.

[9] Xiaojun Zhou. Application of Fuzzy Comprehensive Evaluation Method in Governance Performance Evaluation of Listed Companies[C]. Proceedings of 2011 World Congress on Engineering and Technology vol.08.2011.pp.366-385 